УДК 597.556.331.1

\title{
ОСОБЕННОСТИ МОРФОЛОГИИ ТОЛСТОЩЕКА МИДДЕНДОРФА HADROPAREIA MIDDENDORFFII (ZOARCIDAE) ИЗ ТАУЙСКОЙ ГУБЫ ОХОТСКОГО МОРЯ
}

\author{
Поезжалова-Чегодаева Е. А. \\ ФГБУН Институт биологических проблем Севера ДВО РАН, г. Магадан \\ E-mail: zoarces@mail.ru
}

\begin{abstract}
Изучены пластические, меристические признаки, а также особенности окраски толстощека Миддендорфа Hadropareia middendorffi из Тауйской губы Охотского моря. Установлено, что тауйские толстощеки отличаются по ряду ранее приводимых для вида признаков: пропорциям головы, размерам грудных плавников, а также количеству лучей в спинном плавнике. Показано, что границы как минимальных, так и максимальных значений пластических признаков толстощека Миддендорфа расширились, в отношении же меристических признаков пределы изменчивости коснулись только минимальных значений.
\end{abstract}

Ключевые слова: толстощек Миддендорфа, Hadropareia middendorffi, морфология, Тауйская губа, Охотское море.

DOI: $10.34078 / 1814-0998-2020-2-87-92$

Род толстощеков Hadropareia Schmidt, 1904, относящийся к подсемейству Gymnelinae (Zoarcidae, Pisces), отличается от других родов своей группы, имеющих брюшные плавники, отсутствием зубов на небных костях и их наличием на сошнике (Матюшин, 1989). Этот эндемичный для Охотского моря род объединяет два вида. Один из них, толстощек Миддендорфа Hadropareia middendorffi, описан с литорали Шантарских островов. Он относится к категории обычных представителей литоральных рыб Охотского моря. Его ареал охватывает участки охотоморского побережья от Шантарских островов на восток до Пенжинской губы и далее к югу до Усть-Хайрюзова на Западной Камчатке (Шмидт, 1950; Линдберг, Красюкова, 1975; Черешнев и др., 2001; Федоров и др., 2003; Балушкин и др., 2012). В Тауйской губе этот вид встречается повсеместно, в основном в приливно-отливной зоне (ПоезжаловаЧегодаева, 2016б). Второй вид, H. semisquama$t a$, имеет значительно меньший ареал и известен пока только в охотоморских водах Южных Курильских островов - Шикотан и Итуруп (Матюшин, 1989).

Сведения о морфологии толстощеков немногочисленны и в основном представляют собой краткие описания (Линдберг, Дулькейт, 1929;

(C) Поезжалова-Чегодаева Е. А., 2020
Шмидт, 1950; Линдберг, Красюкова, 1975; Anderson, 1994). Наиболее полная внешнеморфологическая характеристика $H$. middendorffi из разных районов северной части Охотского моря, а также H. semisquamata дана в работе В. М. Матюшина (1989). Особенности строения скелета $H$. middendorffii освещены М. Е. Андерсоном (Anderson, 1994). Кроме того, некоторые пластические, меристические и остеологические признаки толстощека описаны в публикациях автора (Поезжалова-Чегодаева, 2015, 2016a).

Целью настоящей работы является изучение морфологии (пластических, меристических признаков, а также особенностей окраски) толстощека Миддендорфа из Тауйской губы для расширения представлений об изменчивости данного вида.

\section{МАТЕРИАЛ И МЕТОДИКА}

Материал был собран в северной части Охотского моря, в Тауйской губе, в период с июля по август 2015-2016 гг. Рыб отлавливали руками под камнями и в литоральных лужах во время отлива. Изучение морфологических признаков проведено на фиксированных в 70\%-ном этиловом спирте, а особенностей окраски - на свежих экземплярах. Всего обработано 57 рыб, из них 23 самца, 30 самок и 4 неполовозрелые особи. 
Для подсчета количества лучей в плавниках и позвонков, были изготовлены 23 ализариновых препарата (Potthoff, 1984) экземпляров длиной $T L$ 120.1-260.7 мм. Строение осевого скелета изучено по рентгенограммам 7 экземпляров длиной $T L$ 127.1-216.5 мм. Количество лучей в грудном плавнике и жаберных лучей подсчитывали на обеих сторонах тела.

Результаты обработаны статистически при помощи стандартного пакета программ (Microsoft Excel 2007) и приведены в виде среднего значения и его ошибки. Достоверность различий морфометрических показателей исследуемой выборки и ранее описанных экземпляров определена с помощью критерия Стьюдента (Лакин, 1980).

В статье приняты следующие буквенные обозначения: $T L$ - полная длина тела, $c$ - длина головы, $H_{D}$ - высота тела у начала спинного плавника, $H_{A}$ - высота тела у начала анального плавника, $a D$ - антедорсальное расстояние, $a A$ - антеанальное расстояние, io - межглазничное расстояние; $o$ - наибольший диаметр глаза, $a о$ - длина рыла до переднего края глаза, ро - заглазничная длина, $\operatorname{lm} x$ - длина верхней челюсти, lmd - длина нижней челюсти, $l P$ - длина грудного плавника, $l V-$ длина брюшного плавника, $h P$ - высота основания грудного плавника, $h b r$ - высота жаберного отверстия, $h c$ - высота головы, $w t$ - ширина тела у основания грудных плавников, $w c-$ ширина головы при закрытом рте и нормально прижатых жаберных крышках. $A, D, P$ - количество лучей в анальном, спинном и грудном плавниках; vert. a. - число туловищных позвонков, vert. c. - количество хвостовых позвонков, vert. - общее количество позвонков.

\section{РЕЗУЛЬТАТЫ И ОБСУЖДЕНИЯ}

Толстощек из Тауйской губы характеризуется следующими признаками: $D$ 105-112 (109.1 \pm 0.27$), A$ 84-92 (89.0 0.35$), P$ 14-16, жаберных лучей 6-8; общее количество позвонков 107-115 (111.5 \pm 0.27$)$. Полученные меристические характеристики исследуемых экземпляров сопоставимы с ранее описанными из разных районов северной части Охотского моря: Шантарских островов, Гижигинской, Пенжинской и Тауйской губ, а также из зал. Константина. Исключением является количество лучей $D$, средние значения которого у тауйских экземпляров достоверно ниже ранее известных для этого вида (Линдберг, Дулькейт, 1929; Солдатов, Линдберг, 1930; Линдберг, Красюкова, 1975; Матюшин, 1989).

Меристические и пластические признаки исследованных рыб представлены в таблице.

Описание. Тело низкое, удлиненное, сжатое с боков, постепенно сужается к хвосту (рис. 1).
$H_{D}$ укладывается в 12.0 раз в $T L$. Кожа вдоль всего тела вертикально морщинистая, полностью лишена чешуи. Рот большой, конечный, задний край верхней челюсти достигает вертикали середины глаза, а у крупных экземпляров доходит до вертикали заднего края глаза. Губы толстые, мясистые, непрерывные, высота верхней губы примерно в 2 раза больше нижней. У крупных экземпляров (более 150.0 мм $T L$ ), в основном у самцов, имеются хорошо выраженные вздутия в заглазничной зоне и в области щек. Голова небольшая, относительно низкая, ее высота $(h c)$ немного меньше ее ширины $(w c)$. Верхний ее контур впереди глаз резко понижается. Межглазничное пространство и затылок плоские. Глаза овальной формы, небольшие, их верхний край немного выступает из верхнего профиля головы, а продольный диаметр немного больше межглазничного расстояния. Нижний край жаберного отверстия достигает середины основания грудного плавника.

Спинной плавник единый, состоит из 105 112 (среднее $109.10 \pm 0.27$ ) членистых лучей, большинство из которых ветвистые, и лишь 3-4 последних не ветвятся. Его высота по всей длине почти одинакова, в 1.5-2 раза больше высоты анального плавника, и уменьшается только вблизи хвостового плавника. Первый птеригофор $D$ располагается между 1-2-м позвонками. Анальный плавник состоит из 84-92 (среднее $89.01 \pm 0.35)$ членистых лучей, 3-4 последних не ветвятся. Основания спинного и анального плавников сливаются с основанием хвостового без выемок. Хвостовой плавник короткий, содержит 7-8 (7.34 \pm 0.19$)$ членистых лучей: $2-3$ $(2.3 \pm 0.15)$ - на эпаксиальной и $3-4(3.7 \pm 0.31)-$ на гипаксиальной пластинках, а также имеется 1 epurale, поддерживающее еще 1 или 2 луча.

Позвонки асимметричные, со сдвинутой вперед перетяжкой. Всего их количество составило

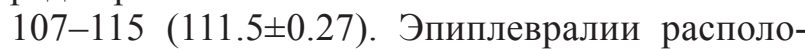
жены по 14-19-й позвонок.

Парные плавники небольшие. Грудной плавник округлой формы, его длина примерно равна заглазничному расстоянию; брюшной торакальный, расположен несколько впереди основания грудного, а его задний край находится на вертикали основания последнего. В грудном плавнике 14-16 ветвистых лучей (среднее $14.7 \pm 0.24$ ). В брюшных по 3 членистых ветвистых луча, последний, внутренний длиннее остальных.

Сейсмосенсорная система головы образована хорошо заметными у фиксированных экземпляров порами. У всех исследованных особей с каждой стороны по 2 носовые поры (среднее $2.0)$, в заглазничном канале слева 2-3-й и справа 3-й поры (среднее 2.9/3.0 соответственно), в подглазничном 6 с обеих сторон. Количество 
Морфометрические признаки толстощека Миддендорфа из Тауйской губы Охотского моря в сравнении с ранее опубликованными данными (Матюшин, 1989)

Morphometric characteristics of Middendorff's eelpout from the Tauysk Bay of the Sea of Okhotsk, compared to previously published data (Matyushin,1989)

\begin{tabular}{|c|c|c|c|c|c|}
\hline \multirow{2}{*}{ Признак } & \multicolumn{2}{|c|}{ Данные автора } & \multicolumn{2}{|c|}{ Данные Матюшина, 1989 г. } & \multirow{2}{*}{ t-критерий } \\
\hline & $\lim$ & $\mathrm{M} \pm \mathrm{m}$ & Lim & $\mathrm{M} \pm \mathrm{m}$ & \\
\hline$T L$, мм & $42.7-283.0(57)$ & $135.9 \pm 5.90$ & $54.0-248.5(57)$ & - & - \\
\hline \multicolumn{5}{|c|}{ В \% от длины тела $T L$} & \\
\hline$a A$ & $32.5-41.4(57)$ & $36.99 \pm 0.24$ & $31.2-41.8(57)$ & $37.43 \pm 0.21$ & 1.38 \\
\hline$a D$ & $13.1-20.1(57)$ & $16.50 \pm 0.17$ & $14.3-22.5(57)$ & $16.95 \pm 0.19$ & 1.77 \\
\hline$c$ & $11.8-21.0(57)$ & $15.88 \pm 0.30$ & $12.9-22.1(57)$ & $16.15 \pm 0.18$ & 0.77 \\
\hline po & $6.4-13.2(57)$ & $9.49 \pm 0.16$ & $7.1-13.4(56)$ & $9.91 \pm 0.14$ & 1.98 \\
\hline $\operatorname{lm} x$ & $3.3-7.0(57)$ & $5.68 \pm 0.13$ & $4.6-10.9(57)$ & $5.96 \pm 0.15$ & 1.41 \\
\hline $\operatorname{lmd}$ & $3.8-7.1(57)$ & $5.46 \pm 0.11$ & $5.9-11.3(56)$ & $7.76 \pm 0.14$ & 12.92 \\
\hline$H_{A}$ & $6.4-10.4(57)$ & $8.52 \pm 0.10$ & $6.7-10.5(57)$ & $8.34 \pm 0.11$ & 1.21 \\
\hline$H_{D}$ & $5.1-10.7(57)$ & $8.36 \pm 0.12$ & $6.5-9.5(57)$ & $8.27 \pm 0.10$ & 0.58 \\
\hline$l P$ & $6.3-10.9(57)$ & $8.45 \pm 0.14$ & $7.9-11.1(57)$ & $9.02 \pm 0.09$ & 3.42 \\
\hline$h P$ & $2.2-5.5(57)$ & $3.33 \pm 0.07$ & $2.6-5.2(55)$ & $3.49 \pm 0.06$ & 1.74 \\
\hline$h b r$ & $1.9-4.6(57)$ & $3.26 \pm 0.06$ & $2.4-4.4(56)$ & $3.29 \pm 0,05$ & 0.38 \\
\hline$h c$ & $4.6-9.0(57)$ & $7.04 \pm 0.12$ & $6.1-9.7(57)$ & $7.45 \pm 0.10$ & 2.62 \\
\hline$w t$ & $3.2-10.0(57)$ & $6.17 \pm 0.17$ & $3.2-10.3(45)$ & $5.45 \pm 0.12$ & 3.46 \\
\hline$w c$ & $4.2-11.9(57)$ & $8.83 \pm 0.17$ & $5.4-11.2(45)$ & $8.16 \pm 0.20$ & 2.55 \\
\hline \multicolumn{5}{|c|}{ В \% от длины головы $c$} & \\
\hline$o$ & $11.0-25.2(57)$ & $17.89 \pm 0.44$ & $11.5-22.5(55)$ & $17.32 \pm 0.33$ & 1.04 \\
\hline$a o$ & $14.0-25.1(57)$ & $21.29 \pm 0.26$ & $16.5-27.4(26)$ & $22.72 \pm 0.47$ & 2.66 \\
\hline$H_{A}$ & $32.7-69.8(57)$ & $53.48 \pm 1.22$ & $36.3-68.4(57)$ & $52.00 \pm 0.88$ & 0.98 \\
\hline$H_{D}$ & $37.9-69.7(57)$ & $53.34 \pm 1.08$ & $38.4-63.9(57)$ & $51.45 \pm 0.71$ & 1.46 \\
\hline io & $8.4-20.5(57)$ & $15.02 \pm 0.36$ & $9.4-22.4(52)$ & $16.20 \pm 0.43$ & 2.10 \\
\hline$l P$ & $43.7-66.9(57)$ & $55.85 \pm 0.66$ & $42.1-65.6(57)$ & $56.12 \pm 0.62$ & 0.30 \\
\hline$h P$ & $15.5-30.0(57)$ & $22.17 \pm 0.42$ & $15.3-30.0(55)$ & $21.67 \pm 0.37$ & 0.89 \\
\hline$l V$ & $9.5-25.4(57)$ & $14.68 \pm 0.44$ & $10.8-23.5(57)$ & $16.08 \pm 0.23$ & 2.82 \\
\hline$h b r$ & $13.8-27.0(57)$ & $21.86 \pm 0.38$ & $13.7-25.9(56)$ & $20.56 \pm 0.35$ & 2.52 \\
\hline$h c$ & $34.4-58.6(57)$ & $46.77 \pm 0.66$ & $33.2-55.3(57)$ & $46.31 \pm 0.57$ & 0.53 \\
\hline$w t$ & $24.0-50.0(57)$ & $37.61 \pm 0.94$ & $19.4-44.2(45)$ & $34.22 \pm 0.83$ & 2.70 \\
\hline$w c$ & $27.6-66.6(57)$ & $51.04 \pm 1.16$ & $32.7-67.8(45)$ & $51.07 \pm 1.41$ & 0.02 \\
\hline po & $46.6-68.6(57)$ & $60.46 \pm 0.54$ & $45.8-76.3(56)$ & $61.35 \pm 0.58$ & 1.12 \\
\hline \multicolumn{5}{|c|}{ Счетные признаки } & \\
\hline$D$ & $105-112(30)$ & $109.10 \pm 0.27$ & $107-114(28)$ & $110.57 \pm 0.35$ & 3.33 \\
\hline$A$ & $84-92(30)$ & $89.01 \pm 0.35$ & $85-93(29)$ & $89.69 \pm 0.38$ & 1.32 \\
\hline$P / P^{\prime}$ & $14-16(23)$ & $14.60 / 14.70 \pm 0.24 / 0.23$ & $14-16 / 12-16(13 / 49)$ & $14.53 / 14.63 \pm 0.18 / 0.12$ & $0.23 / 0.27$ \\
\hline$r . b r / r \cdot b r^{\prime}$ & $6-8(33)$ & $6.91 / 7.01 \pm 0.31 / 0.35$ & $6-8 / 6-8(41 / 47)$ & $7.05 / 6.96 \pm 0.05 / 0.04$ & $0.45 / 0.14$ \\
\hline vert. $a$. & $23-26(24)$ & $24.60 \pm 0.10$ & $24-26(43)$ & $24.79 \pm 0.09$ & 1.41 \\
\hline vert. $c$. & $82-90(24)$ & $86.04 \pm 0.22$ & $81-90(42)$ & $86.02 \pm 0.27$ & 0.06 \\
\hline vert. & $107-115(24)$ & $111.51 \pm 0.27$ & $106-115(42)$ & $110.86 \pm 0.29$ & 1.64 \\
\hline
\end{tabular}

Примечание. $\mathrm{M} / \mathrm{m}$ - среднее значение показателя / его ошибка; в графе «t-критерий» жирным шрифтом отмечены достоверно различимые признаки $(p<0.05)$; в скобках - количество экземпляров.

нижнечелюстных пор 3-4 (3.9 с каждой стороны), предкрышечных пор по 4 с каждой стороны. Межглазничная пора была обнаружена только у двух экземпляров $T L 85$ и 91 мм.

Окраска. В окраске тела нет четко выраженного рисунка, имеются лишь слабозаметные, размытые штрихи и пятна (см. рис. 1). Окраска фиксированных экземпляров от темного-серого до желтовато- и зеленовато-серого, нижняя че- люсть и брюхо до начала анального плавника грязно-белые. Спинной и грудные плавники светло-коричневые с оранжевым отливом. Нижняя челюсть и брюхо пигментированы слабо, анальный и брюшные плавники светлые, серовато-белые. Щеки, жаберные крышки, межглазничное пространство, верхняя губа окрашены в более темные тона, от серо-коричневого до темно-серого. У крупных особей (от 130 мм $T L$ ), 


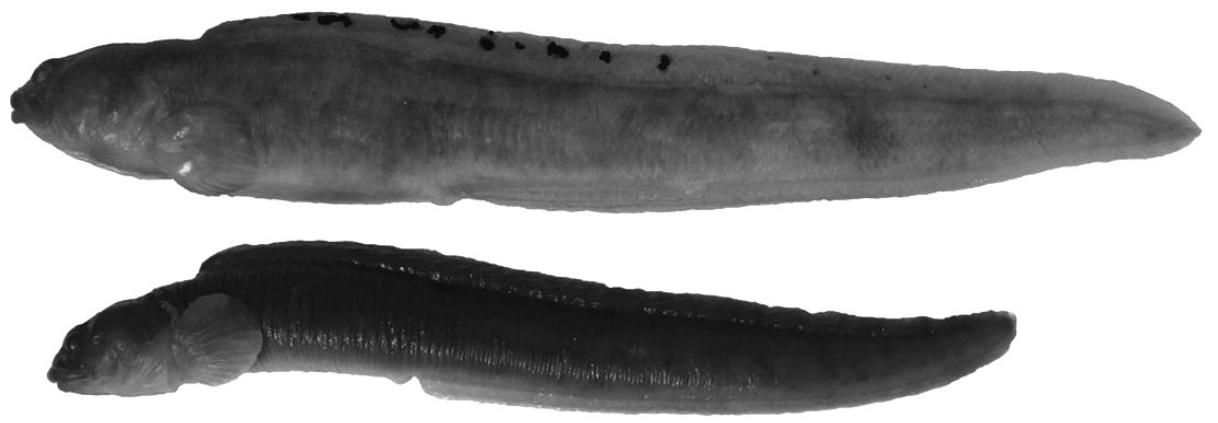

Puc. 1. Толстощек Миддендорфа (полная длина тела 186.3 и 148.7 мм)

Fig. 1. Middendorff's eelpout (total body length $T L 186.3$ and $148.7 \mathrm{~mm}$ )

большей частью у самцов, на спинном плавнике в верхней его части наблюдаются черные, хорошо заметные пятна неправильной формы разных размеров, не группирующиеся в определенный рисунок. Их количество сильно варьирует. Из всей исследуемой выборки только у одной самки также были обнаружены несколько черных пятен. У только что пойманных особей спинной и грудные плавники прозрачные, с оранжевой окантовкой по краям. У основания спинного плавника, в нижней его части, а также в области щек, под глазами в районе верхней челюсти и затылочной комиссуры имеются голубовато-перламутровые пятнышки неправильной формы, исчезающие при фиксации рыб. Кожа на брюхе у живых экземпляров прозрачная, светло-серая, тонкая, с хорошо заметными кровеносными сосудами.

Ротовая и жаберная полости у фиксированных экземпляров светлые, грязновато-белые, иногда со слабой желтизной. Брюшная полость всегда более темная, часто светло-коричневатая, иногда также с желтым отливом. Желудок светлый, не пигментирован с 2 короткими пилорическими придатками, по длине примерно равными длине глаза. У самцов развиты две гонады, у самок имеется лишь один левый яичник.

В целом экземпляры из Тауйской губы близки по большинству характеристик к описанным ранее в работе В. М. Матюшина (1989) из разных районов северной части Охотского моря (Аянского залива, Пенжинской, Гижигинской и Тауйской губ, Шантарских островов), однако обнаружены и некоторые различия. Толстощеки исследуемой выборки достоверно отличались по ряду пропорций головы $(h c, w t, w c)$, длиной нижней челюсти, а также размерами грудных плавников (см. таблицу). Отметим, что тауйские толстощеки, в отличие от экземпляров, описанных в работе В. М. Матюшина, характеризовались иным соотношением длин верхней и нижней челюстей: у исследованных нами экземпляров, в отличие от ранее описанных, нижняя челюсть была короче верхней. Обнаружен-

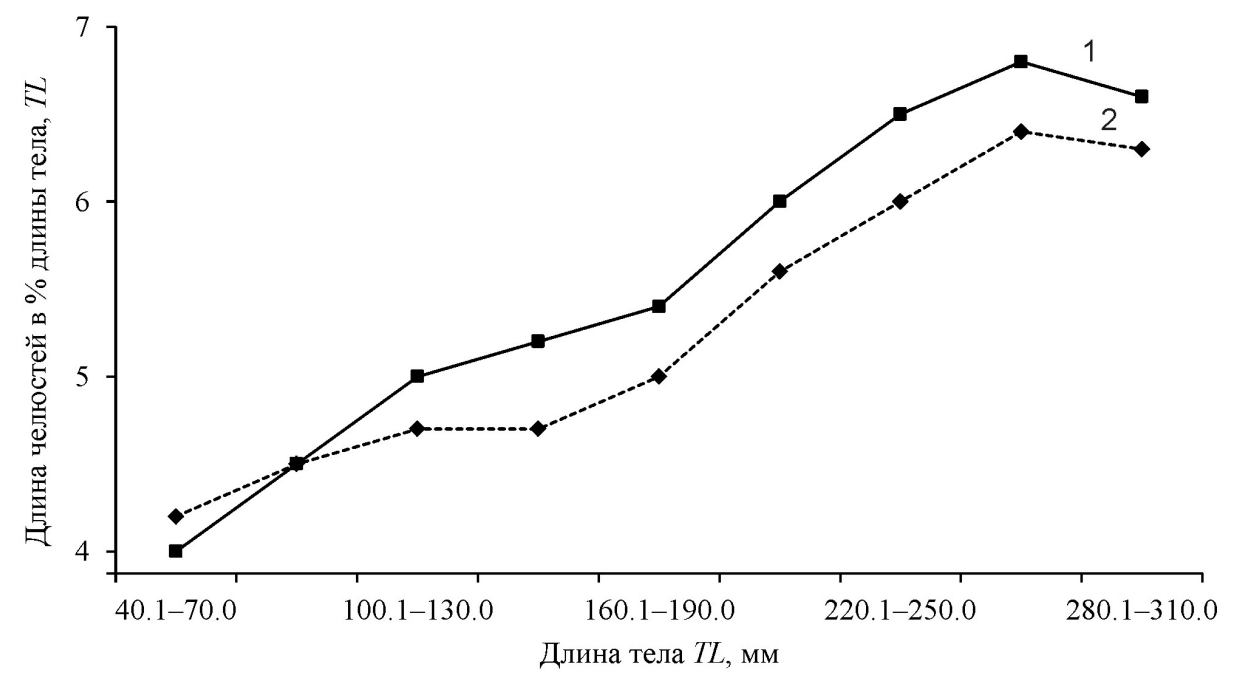

Puc. 2. Зависимость длины челюстей от длины тела $(T L)$ толстощека Миддендорфа: 1 - длина верхней челюсти, 2 - нижней челюсти

Fig. 2. Dependence of the jaw length on that of the Middendorff's eelpout body (TL): 1 - length of the upper jaw, 2 - length of the lower jaw 
ные различия (более широкая голова, короткая нижняя челюсть), скорее всего, связаны с размером изученных экземпляров: в работе В. М. Матюшина (1989) средний размер рыб составил около 100 мм, а большая часть особей была неполовозрелой. Средняя длина тела исследуемых нами рыб составила 135.9 мм, и доля незрелых особей была незначительна - 4 экз. (6\% от общей исследуемой выборки). Как отмечали предыдущие авторы, с увеличением размера особей у данного вида увеличиваются ширина головы в области щек и длина верхней челюсти (Линдберг, Дулькейт, 1929; Матюшин, 1989), что характерно для многих бельдюговых рыб (Anderson, 1994). В нашей выборке относительная длина верхней челюсти также увеличивалась с увеличением размеров особей (рис. 2), в то же время относительная длина нижней челюсти постепенно уменьшалась. Так, у рыб $T L 45.0-$ 55.0 мм верхняя челюсть была незначительно, но все же короче нижней, у рыб $T L$ 70.0-80.0 мм челюсти были примерно одинаковыми, а у особей большего размера верхняя челюсть была заметно длиннее нижней (см. рис. 2).

Средние показатели меристических признаков совпадают с ранее описанными (Линдберг, Дулькейт, 1929; Матюшин, 1989; Anderson, 1994), за исключением количества лучей в $D$, которые так же, как и предельные минимальные значения количества лучей в $A$ и vert. $a$ у тауйских экземпляров, оказались ниже. Обнаружены и некоторые различия в строении $C$ : у большой части исследованных экземпляров (37\%) к единственной epurale прикреплялся лишь один луч $C$, тогда как ранее М. Е. Андерсон упоминал только 2 луча, прикрепленных к epurale (Anderson, 1994).

\section{ЗАКЛЮЧЕНИЕ}

Толстощек Миддендорфа из Тауйской губы Охотского моря характеризуется следующими признаками: $D$ 105-112, A 84-92, P 14-16, r. br. 6-8, vert. 107-115. По пластическим признакам тауйские толстощеки отличаются некоторыми пропорциями головы $(h c, w t, w c)$, длиной нижней челюсти, а также размерами грудных плавников, что, скорее всего, связано с размерами исследованных рыб. Счетные признаки различались по количеству лучей $D$, а также количеству лучей $C$, прикрепленных к epurale.

Исследование пластических характеристик толстощеков из Тауйской губы демонстрирует расширение границ как минимальных значений признаков - aD, c, po, lmx, lmd, lP, hbr, hc,lV,wc, $a o, i o$, так и максимальных $-H_{D}, l V, h b r$. По меристическим признакам тауйские толстощеки показали различия, выходящие за пределы ранее известных границ изменчивости только по минимальным значениям - A, vert. $a$.

\section{ЛИТЕРАТУРА}

Балушкин А. В., Шейко Б. А., Природина В. П. Каталог фондовой коллекции Зоологического института РАН. Класс костистые рыбы (Osteichthyes). Отряд окунеобразные (Perciformes). Подотряд Zoarcoidei. Семейства Bathymasteridae, Zoarcidae, Cryptacanthodidae, Ptillichthyidae, Zaproridae. Подотряд Icosteoidei. Семейство Icosteidae // Исследования фауны морей. СПб. : ЗИН РАН, 2012. Т. 71 (79). 196 с.

Лакин Г. Ф. Биометрия. М. : Высш. шк., 1980. 292 c.

Линдберг Г. У., Дулькейт Г. Д. Материалы по рыбам Шантарского моря // Изв. Тихоокеан. науч.промысл. станции. Владивосток, 1929. Вып. 3. Ч. 1. C. $1-39$.

Линдберг Г. У., Красюкова 3. В. Рыбы Японского моря и сопредельных частей Охотского и Желтого морей. Ч. 4. Teleostomi. XXIX. Perciformes. Blennioidei. Gobioidei. Л. : Наука, 1975. 463 с.

Матюшин В. М. Обзор рода Hadropareia (Zoarcidae) с описанием нового вида Hadropareia semisquamata Andriashev et Matjushin, sp. nov. с литорали Курильских островов // Вопросы ихтиологии. 1989. T. 29, № 4. C. 524-531.

Поезжалова-Чегодаева Е. А. Некоторые данные по морфологии толстощека Миддендорфа Hadropareia middendorffi (Zoarcidae) из Тауйской губы Охотского моря // Материалы XVI междунар. конф. «Сохранение биоразнообразия Камчатки и прилегающих морей». П.-Камчатский : Камчатпресс, 2015. C. 388-391.

Поезжалова-Чегодаева Е. А. Особенности остеологии толстощека Миддендорфа Hadropareia middendorffi (Zoarcidae) из северной части Охотского моря // Геология, география, биологическое разнообразие и ресурсы Северо-Востока России : Материалы III Всерос. конф., посвящ. памяти А. П. Васьковского и в честь его 105-летия (Магадан, 12 14 окт. 2016 г.). Магадан : СВКНИИ ДВО РАН, 2016a. C. 270-272.

Поезжалова-Чегодаева E. А. Первые данные по биологии толстощека Миддендорфа Hadropareia middendorffii (Zoarcidae) из Тауйской губы Охотского моря // Вопросы ихтиологии. 2016б. Т. 56, № 1. C. 58-67.

Солдатов В. К., Линдберг Г. У. Обзор рыб дальневосточных морей // Известия ТИНРО. 1930. Т. 5. $576 \mathrm{c}$.

Федоров В. В., Черешнев И. А., Назаркин М. В., Шестаков А. В., Волобуев В. В. Каталог морских и пресноводных рыб северной части Охотского моря. Владивосток : Дальнаука, 2003. 206 с.

Черешнев И. А., Волобуев В. В., Хованский И. Е., Шестаков А. В. Прибрежные рыбы северной части Охотского моря. Владивосток : Дальнаука, 2001. $197 \mathrm{c.}$

Шмидт П. Ю. Рыбы Охотского моря. М. ; Л. : Издво АH CCCP, 1950. 370 c.

Anderson M. E. Systematics and osteology of the Zoarcidae (Teleostei: Perciformes) // Ichthyol. Bull. J. L. B. Smith Inst. Ichthyol. Grahamstown, S. Africa, 1994. No. 60. P. 1-120. 
Potthoff T., 1984, Clearing and staining techniques, Onthogeny and systematics of fishes / eds. H. G. Moser et al. ASIH Spec. Publ. No. 1. Lawrence, UK. Allen Press

Inc. P. $35-37$.

Поступила в редакиию 21.05.2018 г.

Поступила после доработки 03.02.2020 2.

\title{
MORPHOLOGICAL FEATURES OF THE MIDDENDORFF'S EELPOUT HADROPAREIA MIDDENDORFFII (ZOARCIDAE) FROM THE TAUYSK BAY OF THE SEA OF OKHOTSK
}

\author{
E. A. Poezzhalova-Chegodaeva \\ Institute of Biological Problems of the North, FEB RAS, Magadan
}

\begin{abstract}
Plastic and meristic characteristics, as well as coloration features of the Middendorff's eelpout Hadropareia middendorffii from Tauysk Bay, the Sea of Okhotsk, are studied. It has been establishied that the studied Middendorff's eelpouts differ in several plastic characteristics previously presented for the species: head proportions, size of pectoral fins, and the number of rays in the dorsal fin. It is also shown that the boundaries of both minimum and maximum values of the Middendorff's eelpout plastic features have expanded, while, for meristic features, the limits of variability refer to the minimum values only.
\end{abstract}

Keywords: Middendorff's eelpout, Hadropareia middendorffii, morphology, Tauysk Bay, Sea of Okhotsk.

\section{REFERENCES}

Anderson, M. E., 1994, Systematics and Osteology of the Zoarcidae (Teleostei: Perciformes), Ichthyol. Bull. J. L. Smith Inst. Ichthyol., Grahamstown, S. Africa, 60, $1-120$.

Balushkin, A. V.; Sheiko, B. A.; Prirodina, V. P., 2012, Catalog of the Repository Collection of the Institute of Zoology, Russian Academy of Sciences. Class Osteichthyes. Order Perciformes. Suborder Zoarcoidei. Families Bathymasteridae, Zoarcidae, Cryptacanthodidae, Ptillichthyidae, Zaproridae. Suborder Icosteoidei. Family Icosteidae, Explorations of the Fauna of the Seas, St. Petersburg, ZIN RAS, 71 (79) [In Russian].

Chereshnev, I. A.; Volobuev, V. V.: Khovansky, I. Ye.; Shestakov, A. V., 2001, Fishes of the Northern Part of the Sea of Okhotsk, Vladivostok, Dalnauka [In Russian].

Fedorov, V. V.; Chereshnev, I. A.; Nazarkin, M. V.; Shestakov, A. V.; Volobuev, V. V., 2003, Catalog of Marine and Fresh Water Fishes of the Northern Part of the Sea of Okhotsk, Vladivostok, Dalnauka [In Russian].

Lakin, G. F., 1980, Biometry, Moscow, Vysshaya Shkola [In Russian].

Lindberg, G. U., Dul'keit, G. D., 1929, Data on Fishes of the Shantar Sea, Izvestiya Tikhookeanskoy Nauchno-Promyslovoy Stantsii, Vladivostok, 3, 1, 1-39 [In Russian].

Lindberg, G. U., Krasyukova, Z. V., 1975, Fishes of the Sea of Japan and the Adjacent Parts of the Okhotsk and Yellow Seas, Part 4: Teleostomi, XXIX, Perciformes, Blennioidei, Gobioidei, Leningrad, Nauka [In Russian].

Matyushin, V. M., 1989, Review of Genus Hadropareia (Zoarcidae) with Description of New Species Hadro- pareia semisquamata Andriashev et Matjushin, sp. nov., from the Littoral of the Kuril Islands, Journal of Ichthyology, 29, 4, 524-531 [In Russian].

Poezzhalova-Chegodaeva, E. A., 2015, Some Data in Morphology of the Middendorff's Eelpout Hadropareia middendorffii (Zoarcidae) in Tauysk Bay of the Sea of Okhotsk, Materials of the XVI International Scientific Conf. "Conservation of Biodiversity in Kamchatka and Its Coastal Waters", Petropavlovsk-Kamchatsky, Kamchatpress, 388-391 [In Russian].

Poezzhalova-Chegodaeva, E. A., 2016a, The Osteology Peculiarities of Hadropareia middendorffii (Zoarcidae) from the Northern Sea of Okhotsk, Geology, Geography, Biological Diversity and National Resources of North-East Russia: The $3^{\text {rd }}$ Russian Conference in Commemoration of A. P. Vaskovsky and in Dedication of His $105^{\text {th }}$ Birthday Date (Magadan, October 12-14), Conference Proceedings, Ed. N. A. Goryachev, Magadan, NEISRI FEB RAS, 270-272 [In Russian].

Poezzhalova-Chegodaeva, E. A., 2016б, First Data on Biology of the Middendorff's Eelpout Hadropareia middendorffii (Percoformes, Zoarcidae) in the Tauysk Bay, Sea of Okhotsk, Journal of Ichthyology, 56, 1, 58-67 [In Russian].

Potthoff, T., 1984, Clearing and Staining Techniques, Onthogeny and Systematics of Fishes, Eds. H. G. Moser et al., ASIH Spec. Publ., 1, Lawrence, UK, Allen Press Inc., 35-37.

Shmidt, P. Yu., 1950, Fishes of the Sea of Okhotsk, Moscow, AS USSR [In Russian].

Soldatov, V. K.; Lindberg, G. U.,1930, Review of Fishes of the Far East Seas, Izvestiya TINRO, 5 [In Russian]. 